Canadian Journal of Family and Youth, 11(1), 2019, pp. 234-291

ISSN 1718-9748@ University of Alberta

http://ejournals,library,ualberta.ca/index/php/cjfy

\title{
In Praise of Empathy: \\ The Glue that holds Caring Communities Together in a Fractured World.
}

\author{
Irene G. Wilkinson
}

\begin{abstract}
In a tumultuous world where populism is on the rise as the result of an enraged, disenchanted, misguided and susceptible populace, empathy, one of the most vital of our moral virtues, is in serious jeopardy. Fear, prejudice and the rise of the extreme right has provoked a number of naysayers to draw our attention to what they believe to be the darker side of empathy, its biases and its vulnerability to subversion. This paper examines empathy, what it is, how it feels, the neural and environmental basis for its development, our moral obligation to nurture it in our children and how it may be induced in the case of empathy deficiencies. It considers the influences of gender and hormones on the expression of empathy and its relationship with sympathy and compassion. Also discussed are the properties of empathy as a motivational, socioemotional mechanism, that evokes kindness, caring, compassion and understanding in each of us, and its potential to neutralize the negativism, cruelty, violence and aggression, so prevalent in the world today.
\end{abstract}

\footnotetext{
Although her formal qualifications are in biomedical science (her thesis on methods for demonstrating changes in the lining cells of the human larynx won her a Fellowship of the Institute of Biomedical Sciences in 1973), in addition to cancer research, Irene Gregory Wilkinson has worked for much of her life in fine and performing arts, broadcasting and in educational and social skills support for children at risk. Although "retired", Irene is still heavily involved in music and busy writing and presenting papers to schools and youth groups on the dangers of smoking, the power of music to enhance learning and relationships, the importance of forging meaningful connections with others, the nature of our interdependence and the school family and getting along. She continues her research and writing on the aetiology of bullying and other forms of anti-social behaviour, and to pursue ways of accommodating and mitigating these behaviours by encouraging the creation of communities of compassion and caring.
}

Publications include:

Wilkinson, I.G. (2013). Let there be music: Making a case for using music in schools to enhance relationships and readiness for learning. Canadian Music Educator, 55(1), 28-31.

Wilkinson, I.G. (2016). Why some children come to school with "baggage": The effects of trauma due to poverty, attachment disruption and disconnection on social skills and relationships. The Canadian Journal of Family and Youth, 8(1), 173-203.

Wilkinson, I. G. (2017). Bullying in Canada in the $21^{\text {st }}$ century: the moral obligations of parents, teachers, schools and governments. International Journal of Children's Rights, 25(1), 231-260. 
Wilkinson

\section{Introduction}

Humans have long been aroused by the distress and suffering of others. The experience of empathy is understood to induce prosocial behaviours. Primatologist and ethnologist Dr. Frans De Waal, in his book “The Age of Empathy: Nature’s lessons for a kinder society” (2009), delivers the message that empathy is the glue that holds civilized society together and allows us to experience healthy, satisfying, long-lasting interpersonal relationships. Michele Borba (2001), author, educator and parent, believes empathy to be "the core moral emotion" (p.18) and places it first on a list of seven essential virtues of moral intelligence. Borba feels that empathy might be the perfect antidote for an increasingly cruel, violent and unfeeling world.

Empathy is a motivating socioemotional process specifically involved in our understanding of, and cooperation with, others. The ability to "read" the intentions and emotions of others and to learn from our experiences are critical to our survival. Empathy is necessary for attachment and caregiving since it evokes sympathy, kindness and compassion. Compassion is the extension of affective (emotional) empathy; it is empathy with action and is key in neutralizing negativity and cruelty. Empathy has played a crucial role in preventing acts of violence and terrorism across the world, highlighting its inextricable link to conscience.

Empathy increases the likelihood that we are moved to volunteer more (Konrath \& Grynberg, 2016) and to help those in need. Empathy moves us to view others, including those who are different from ourselves, in a more positive light. Induced empathy has been shown to attenuate prejudice against stigmatized people or groups (Batson, Chang, Orr, \& Rowland, 2002; Vescio, Sechrist, \& Paolucci, 2003).

Despite all the evidence, research and literature to attest to the moral virtues of empathy, alarmingly, there are those who contend that there is too much empathy in the world and that we 
should replace it with something else. With the rise of the populist movement, the steady diet of cynicism, narcissism, negativism and abusive rhetoric heard on our radios and appearing on our screens each day and the erosion of empathic reasoning in government decision making, questioning the value of empathy is fast becoming a fashionable trend.

We need to scrutinize empathy, to look at its roots, examine its properties as a moral virtue and the influences that enhance its development. We must consider our obligations, as parents and teachers, to model empathy, to nurture and preserve it in our children, for without our help, there's the risk it may become dormant. Just as healthy growth requires nourishment, so the soft skills like empathy, kindness, caring, thoughtfulness and concern need to be nurtured (Wilkinson, 2017). We need to ask what kind of a world we want our children to inherit and challenge ourselves to do our part in helping them to shape it.

Our survival as a human race depends upon how much we care for each other, how well we get along together in a fractured world.

\section{What is Empathy?}

It was not until humans began to contemplate their innermost thoughts and feelings and those of others, around the beginning of the $20^{\text {th }}$ century, that they were able to recognise empathy. In fact, the word empathy was not part of our human vocabulary until 1909 (Rifkin, 2009).

Empathy or "fellow feeling" is fraught with definitional issues. Nevertheless, most researchers agree that it is the innate ability to "read" the intentions and emotions of others. Empathy is deeply related to morality and its presence facilitates prosocial behaviour and inhibits anti-social behaviour (Williams, O’Driscoll, \& Moore, 2014). 
Psychologist and author, Clive R. Hollin, (1994), describes empathy as the ability to see the world, including one's own behaviour, from another person's point of view. Author and psychologist Robert Hogan (1969) suggests that empathy is the act of constructing for oneself another person's mental state. Psychologist Martin Hoffman (1987), defines empathy as an affective response more appropriate to someone else's situation than to our own. American economic and social theorist, Jeremy Rifkin (2009) describes empathy as the ability to show solidarity with one another and researchers Nancy Eisenberg and Janet Strayer (1987) regard empathy as an emotional response that stems from another's emotional state or condition, and that is congruent with the other's emotional state or situation.

Some think of empathy as a purely cognitive mechanism that involves imagining another's point of view or internal experience (Borke, 1971; Deutsch \& Madle, 2009). Other researchers think of it as a more affective process which includes emotional matching (Batson, 1990; Panskepp, 1998; Watt, 2007), and describe the vicarious experiencing of the emotional state of another as emotional contagion or affective resonance (Feshbach \& Roe, 1968; Watt, 2007). Some investigators outline the presence of two distinct types of empathy both cognitive and affective and others see these more as overlapping than separate (Hoffman, 1984).

Scottish economist, moral philosopher and author, Adam Smith (2006), postulated that we have two empathic capacities that complement each other: affective or emotional empathy (a vicarious emotional response to, or empathic concern over, another's situation) and cognitive empathy (mental perspective taking, the ability to take the emotional perspective of another in a certain context, while maintaining the distinction between their perspective and one's own). This is linked to theory of mind, which also helps us to assess how we should respond.

Morelli, Rameson and Lieberman, (2014) refer to three empathic elements. They include 
In Praise of Empathy

prosocial motivation as the third mechanism, sometimes referred to as "empathy with action" or compassion. Similarly, Derntl, Finkelmeyer, Voss, Eickhoff, Kellerman, Schneider and Habel (2012) speak of three components: emotion recognition, perspective taking and affective responsiveness.

Most scholars accept that without emotion recognition, empathy fails. Unless we understand our own emotions, it is next to impossible to understand the emotions, and take the perspectives, of others. Most believe that all the recognized components of empathy come as a package and work in tandem. It is also possible to experience, within these parameters, reflective empathy - looking back on something we have experienced in relation to another's situation and feeling it again as intensely as if it has just happened.

American social psychologist C. Daniel Batson coined the expression "empathic concern" (Batson, Ahmad, \& Stocks, 2004) which is not a single emotion but includes experiencing an array of emotions including empathy and feelings of sympathy, compassion, sorrow, sadness, distress, concern and grief. Empathic concern is other-oriented in the sense that it involves feeling for others.

Some scientists believe that we cannot feel true empathy without prior personal experience of a similar situation to that of another, while others have found that prior experience is not required, that we don't need to fully understand the situation in order to recognise the plight of someone in distress.

Seeing the plight of another is often sufficient to evoke feelings of concern in us and triggers our empathic response (Batson, 2011; Hodges, 2005; Jackson, Brunet, Meltzoff, \& Decety, 2006). Similarly, witnessing elation in someone can elicit a feeling of joy and celebration in us. Once we have experienced empathy in response to another's distress or 
elation, then we can begin to understand what led to their situation and decide on a course of action (hopefully, rational compassion or celebration). According to author J.K. Rowling (2008), author of the best-selling Harry Potter book series, "Unlike any other creatures on this planet, human beings can understand without having experienced. They can think themselves into other people's places". There is little doubt, however, that prior experience does heighten our appreciation of others' circumstances and enhances our capacity for empathy (Hodges, Keil, Kramer, Veach, \& Villanueva, 2010).

Whether we see suffering or elation, when we empathise, we share the "feelings experience" even before we fully understand the circumstances. According to Frans de Waal (2009) the bodily reaction of empathy comes first, frequently followed by cognitive understanding of the situation. This happens automatically in response to what it is we witness. We feel empathy in response to how someone else is feeling rather than why they are feeling this way.

There are those who challenge the seemingly involuntary nature of empathy and who believe that people's mindsets are the engines which powerfully affect whether they exert the effort to empathize (Schumann, Zaki, \& Dwek, 2014). There is much evidence pointing to empathy's involuntary nature however and the idea that we are pre-wired to feel the pain or elation of others certainly holds weight. Empathy surely feels like an involuntary response since we don't choose to feel it; rather like a startle reflex, it just happens. It is our emotional reaction to what we witness and our initial response, our first instant of perception, appears to be spontaneous.

While feeling empathy may be out of our control, what is in our control is our ability to choose whether we apply it and take appropriate action (herein lies empathy's potential property 
as a virtue), or whether we simply ignore it, brush it aside. If our empathy has been nurtured, even if we choose to disregard it, it still happens to us; we feel something inside in direct response to the emotional signals of another.

Structures and networks in the social brain are highly related to empathy (Yamasue, Kuwabara. Kawakubo, \& Kasai, 2009). Neuroscientists have been able to demonstrate a neuroemotional response involving our automatic recruiting of brain regions associated with theory of mind (Schulte-Ruther, Markowitsch, Fink, \& Piefke 2007), together with the help of mirror neurons (nerve cells that fire in someone performing an action and which fire, concomitantly, in another who is observing the performance of that action) (Jackson, et al., 2006; Lamm, Decety, \& Singer, 2011; Zahn-Waxler, Radke-Yarrow, Wagner, \& Chapman, 1992).

In other words, when someone is performing a task or feeling an emotion, and we are observing him, the neurons that are being lit up in his brain as he performs the task or feels the emotion, are the same kind of neurons lighting up in our brains merely from observing him. This is not a matter of our having to imagine what he is experiencing. Our first empathic response is automatic and immediate. After empathy has struck, our imagining and thinking about what he is experiencing does, in fact, render our empathic experience even more profound, but the first stage of empathy appears to be involuntary.

The human brain has multiple mirror neuron systems that specialize in carrying out and understanding not only the actions of others but also their intentions, the social meaning of their behaviour and their emotions. Experiments in neuroscience lead us to understand how, through the firing of mirror neurons, we are actually able to experience the pain or elation of others. Empathy, for both positive and negative emotions, selectively activates regions of the brain associated with positive and negative affect, respectively. People who rank high on the empathy 
scale have particularly active mirror neuron systems (Pfeifer, Iacobonia, \& Mazziotta, 2008).

Functional magnetic resonance imaging (fMRI) has revealed that merely observing images can activate brain regions associated with first hand experience of pain (Decety, Michalska, \& Akitsuki, 2008a). Clear images of brain activity involved with empathy allow researchers to construct theories, paradigms and studies to measure how our understanding of one another affects our social behaviour. However, the affective state of empathy is somewhat broader than mere shared experience and there is always a need to measure brain activation of many cognitive and behavioural constructs. Neural systems for affective and cognitive empathy, have been shown to heavily influence each other. These are likely the mechanisms that underlie this complex and intriguing phenomenon that connects us and allows us to feel and to care for each other.

No matter its underpinnings, empathy is generally understood to be an emotional trait but the roots of our capacity for empathy lie not only in our mirror neurons but also in our life experience (see 'The Development of Empathy'). De Waal (2009) explains how the body produces internal sensations and communicates with other bodies. From this communication we construct social connections and an appreciation of the surrounding reality. Humans feed off the transferring of emotions that happens in our face-to-face interactions.

Empathy, like conscience, is about listening to our hearts, something that Professor Paul Bloom (2016) says we should avoid. It is a gift that lives inside us and if we have had the good fortune to have parents or primary caregivers who nurtured it, we have the profound ability to imagine walking in someone else's shoes, seeing through someone else's eyes. It is the power we have to identify ourselves, mentally, with someone else, whether they are celebrating or suffering, the ability to fully comprehend another. 
In Praise of Empathy

\section{How Does Empathy Feel?}

The experience of empathy may well be unique for each of us, but it is still something we feel inside, something that happens to $u s$ in response to the emotional signals from another. Most describe it as a physical sensation felt between the heart and the gut, sometimes reaching the extremities. Sometimes the heart skips a beat and people may tear up. It may be anything from a wince (often as a result of seeing someone inflicting pain on another), a deep, penetrating ache or a jolt, a kneejerk or a shock wave, a surge of adrenaline (more usually when someone's suffering confronts us unexpectedly) to a wave of warmth, excitement and pleasure in response to another's elation.

Empathy happens when we see someone (or some people) in distress and suffering or experiencing joy. Unlike sympathy, empathy is not restricted to sad or tragic events; we sometimes only associate it with pain and suffering and forget that feeling and sharing the joy and success of another is also an empathic experience.

Even if the cause of someone's distress or joy is not immediately clear to us; even if she is experiencing something we have not, ourselves, faced, we still feel something happening inside us in response to the emotion we see in her. It is our response to how someone is feeling (anguish or elation) not why they are feeling this way (see 'Empathy Versus Sympathy').

Sometimes the situations of others are immediately clear to us. We may tear up when we see people we've never met saying goodbye to family members or friends at an airport. We may tear up, feel deep joy and elation, when we see families and friends greeting one another at an airport or someone achieving success at something they've worked very hard to achieve. In the sadness or joy of someone else, we actually experience something physical and emotional happening to $u s$ ! 
Wilkinson

\section{The Development of Empathy}

The development of empathy and our compassion for others depends on our ability to "read" social cues, to be sensitive to and identify the feelings of others.

Our descriptions of empathy should not be fanciful. Empathy is an emotional response and research has shown that it has a neurological foundation. The development of empathy and compassion, reading and identifying with the non-verbal nuances of others' emotions, involves similar learning processes which have a neural basis. The insula cingulate cortex of the brain is part of the limbic system (emotion formation, processing, learning and memory) and has been identified as a key mechanism involved in our experiencing the emotional state of others (Dawes et. al., 2012).

No matter its roots, empathy is a very real, profound and complex phenomenon which has been found to emerge naturally in early childhood. Experiments with newborns confirm that they are likely to cry more when they hear recordings of other babies crying. Empathic distress or concern for family members has been demonstrated in healthy developing infants, between the ages of 12 to 24 months (see 'Gender differences').

Children are born with a built-in advantage for their moral development. Long before a child can understand intellectual concepts like morality, her/his moral compass begins to form as emotional brain circuits are wired, creating gut reactions which will eventually help to guide decision-making. Human interaction and experience play a critical role in brain development especially in the early years of life. The nature of human interaction sets the stage for everything children learn about the world and how they respond to it. Positive interaction stimulates brain growth and development and maximizes a child's potential for learning, self-regulation and his response to stress. 
We are shaped therefore, not only by our genetic inheritance (neural networks and temperament), but by our family values and our early life experiences with those closest to us. American psychiatrist, Bruce Perry (1997), reports that experience in the first three years of a child's life are pivotal in the development of, and capacity for, empathy. How children are treated by their primary caregivers is a social determinant of which way their empathy development goes.

However, there are no guarantees that empathy will be nurtured and become an important part of each child's healthy social development. Moral compass development relies on the wiring of empathic and social brain networks in response to essential nurturing childhood experiences. Without necessary nurturing, empathy may become stifled or even dormant. This vital nurturing process is the responsibility of parents or primary caregivers and must continue, at an age-appropriate level of understanding, over a long period of time. Where parents, for whatever reason, are not able to provide appropriate nurturing, it behoves schools to take up the slack (see 'Nurturing Empathy - The Moral Obligations of Parents, Teachers and Schools').

Empathy is an emotional response and emotion is an integral part of memory, learning and cognition. Social neuroscience research provides support for the crucial role that emotion plays in neural functioning and healthy human development. But in order to respond to others with empathic concern we need other information too. We need a complete understanding of our own feelings and emotions and to overcome our negative, fearful reactions, particularly when we see another in pain, so that we can move into supportive action (compassion). All this is part of the essential nurturing required in order to fully develop our capacity for empathy. Absence of empathy leads to apathy and indifference. Empathy is crucial to the development of compassion! 
It is natural for humans to crave connections with others. Sometimes called the "soft skills", empathy, compassion, kindness, tolerance and concern for others are the essential building blocks for cultivating strong interpersonal relationships (Wilkinson, 2016). The foundation for empathy is understanding emotions (Borba, 2001). Children learn what the adults in their lives teach them. Those whose empathy development has been nurtured by their primary caregivers, progress to master more abstract social skills by osmosis, since they are raised in caring environments with appropriate role models (Wilkinson, 2016).

\section{Gender Differences}

Although both males and females begin their lives with a natural capacity for empathy, since females generally play a greater role in child-rearing and bonding and have always had to be in tune with the feelings and needs of their non-verbal offspring, it is often assumed that the female capacity for empathy is greater than that of males. Differences in empathic capacity between males and females seem to manifest themselves long before socialization becomes a factor. Zahn-Waxler et al., (1992) observed girl babies looking, for a longer period, at faces than did boy babies, who looked longer at suspended mechanical mobiles. Girl babies were more likely than boy babies to cry when they heard another baby cry. Female children were seen to be better at reading facial expressions than their male counterparts and showed a greater response to humour (Leibenluft, Gobbini, Harrison, \& Haxby, 2004). When measuring reactions to distressed family members in older children, girls were seen to look more at the other's face, providing physical comfort, and more often expressing concern, such as asking "Are you okay?" Boys were found to be less attentive to the feelings of others, more action-and-object oriented, rougher in their play, and less inclined to social fantasy games. They preferred collective action, 
such as building something together.

In 2002, clinical psychologist, Simon Baron-Cohen, stated that there was strong evidence to prove the greater empathic capacity of females (in studies of "mirror neurons," women tended to have stronger motor responses when watching others than men did). This was confirmed in a further study in 2004 (Baron-Cohen, Richler, Bisarya, Gurunathan, \& Wheelwright). De Waal (2009) found that, growing up, girls are more prosocial than boys, better readers of emotional expressions, more attuned to voices, more remorseful after having hurt someone, and better at taking another's perspective. He points to the more territorial, confrontational and violent nature of many boys and their ability to ignore or supress their empathy.

In 1998, author and psychologist William Pollack reported that boys, just like girls, begin their lives with a natural sense of empathy. By grade two however, he found many boys to be far less sensitive to, and concerned about, the feelings of others. They seemed blind to the anxiety, fear, hurt or pain of those around them and also began to lose their ability to articulate their own emotions and concerns. Many boys come to feel that the only socially acceptable emotion they are permitted to express is anger and that other emotions should be supressed. As anger intensifies the capacity for empathy is greatly diminished. This can, potentially, increase the propensity for violence.

All children experience sadness at some time in their lives. Sadness, even if the cause sometimes seems unreasonable to us, can be very real to a child, and must be acknowledged in order to prevent children going underground with their emotions. Children sometimes need reminding of the value and importance of expressing their emotions and seeking out solutions to their problems. They need to learn that feelings are not bad or good, right or wrong, that it's okay to feel anger, frustration, sadness. Boys need to know that it's okay to cry. Girls need to know 
that it's okay for boys to cry. All children need to see and understand the real benefits of being able to express how they feel and to seek help.

In addition to the fact that our capacities for empathy can be traced back to infancy, studies have confirmed that, even in this liberal age, when it comes to raising children, there are still many parents raising boys very differently from girls (Brody \& Hall, 1993). From the time their children are babies, many parents treat sons and daughters differently, dressing them in gender-specific colors, offering gender-differentiated toys, and expecting different behaviours and emotional responses from boys and girls (Thorne, 1993).

While daughters are generally encouraged to be more open and to share their feelings and emotions freely, some parents tend not to discuss feelings and emotions with their sons. They discourage the display of softer skills in boys and, in fact, supress them. These parents encourage stoicism in their sons ("Big boys don't cry"), bringing them up to put on a tough exterior, to swallow their emotions, fears and concerns, maintain a 'stiff upper lip' and keep their feelings to themselves. Boys, as a result, generally have a smaller emotional vocabulary and as they grow older, many are not comfortable talking about emotions and are loathe to take emotional risks.

Many parents still consider sensitivity to be a feminine trait, perhaps even a sign of weakness rather than a strength, and actively discourage it in their sons. Empathy is not often associated with 'manliness' and women are popularly thought to be the more sensitive and empathic gender. Teaching and demonstrating gender specific behaviours has a lasting negative effect on children and often determines their futures. Consequently, males are generally underrepresented in caring professions such as teaching, nursing and social work.

But while women may tear up more readily at the sight of another's pain or elation, more 
recent neurological studies show that the empathic capacity of males is equally as strong as that of females but that most males may apply it more selectively, since they are more likely to see empathy as a weakness, as something that gets in the way of achieving success (a learned behaviour). They may merely have been discouraged from showing empathy of course (Groen, Wijers, Tuchao, \& Althaus, 2013; Michalska, Kinzler, \& Decety, 2013) and it may, consequently, have been stifled. Bringing young boys up to hide their feelings and emotions is a seriously misguided endeavour. It has been said that "Men who have not made peace with the softer side of themselves, make war on women" (anonymous).

However, as with most gender disparities, it needs to be said that there are, in fact, many men who are more empathic than the average woman, and plenty of women who are less empathic than the average man. Also, as men and women grow older, the gaps between their ability to express empathy narrows. Many men whose empathy has been stifled in their younger years, seem to rediscover the softer side of themselves and their capacity for empathy grows with advancing age. This may well be due to hormonal changes - e.g. a reduction in testosterone (see 'The Effect of Hormones'). Changes in testosterone levels happen when younger men become fathers and in older men with advancing age and, possibly, when they become grandfathers. Children have an amazing capacity to evoke empathy in all of us.

\section{The Effect of Hormones}

Changes in the brain and in behaviour are rarely attributable to the actions of a single hormone. Hormonal systems overlap and hormones work in concert with each other in both stimulating and mediating roles. Changes in behaviour reflect combined and widespread changes across multiple hormonal systems which, themselves, interact with each other (Cappola, 
Maggio, \& Ferrucci, 2008). Hormones function interdependently. However, researchers have experimented with individual hormones in their examination of empathy and have produced some definitive results.

Hormones have been shown to increase our ability to infer the internal state of another and it would seem there is a significant link between certain hormones and our capacity for empathy. Four hormones that occur naturally in both males and females and that are known to be associated with socioemotional functioning are considered here: cortisol, oxytocin, estrogen and testosterone,

Cortisol is a hormone released into the bloodstream by the adrenal glands and which travels throughout the body regulating a wide range of processes. It controls blood sugar levels and therefore has a role in regulating metabolism and maintaining salt/water balance, influencing blood pressure and memory formation. In addition, cortisol is known for its anti-inflammatory properties and also plays a role in the development of the foetus. Perhaps cortisol is more commonly known as "the stress hormone" since cortisol surges are triggered in response to fear or stress as part of the "fight or flight" mechanism which prepares the body to react to danger, real or perceived.

Cortisol plays a part in the expression of empathy. Although it is most often associated with anxiety, high cortisol levels have been related to child-initiated social interaction, empathy, social competence and popularity at school (Tennes \& Kreye, 1985) and good social skills (Booth, Granger, \& Shirtcliff, 2008). Empathic concern (the array of feelings associated with empathy) is also correlated with the release of cortisol when we witness someone in some form of distress. When mothers observed their children performing difficult tasks, changes in the children's cortisol levels were reported and were found to be directly associated with changes in 
the cortisol levels in their mothers (Sethre-Hofstad, Stansbury, \& Rice, 2002; Barraza \& Zak, 2009).

Low cortisol levels have been consistently reported in children and youth who demonstrated more callous, anti-social behaviour (Oosterlaan, Geurts, Knol, \& Sergeant, 2005; Popma et. al., 2007) and in disruptive children with early onset aggression (Kariyawasam, Zaw, \& Handley, 2002; McBurnett, Lahey, Rathouz, \& Loeber, 2000) and with similar results in at risk populations.

Oxytocin, a uniquely "social" neuropeptide that regulates neural mechanisms in the social brain, also exerts a significant effect on empathy. It has been labelled a "neurophysiological mechanism of empathic responses" (Konrath \& Grynberg, 2016, p.86) and has been shown to mitigate, even obstruct, stress responses and cortisol surges (Bartz et al., 2010; Cardoso, Ellenbogen, Orlando, Bacon, \& Joober, 2013; Kubansky, Mendes, Appleton, Block, \& Adler, 2012). Oxytocin has also been shown and to have a positive effect on overall health by attenuating inflammation and promoting wound healing (Clodi et. al., 2008; Gouin et. al., 2010).

Oxytocin is, perhaps, best known for its role in reproductive behaviours since it is released during copulation, childbirth, breastfeeding, social bonding and caregiving (Carter, 1992, 1998). Although, traditionally, it has been associated with reproductive processes (Pedersen, 1997), oxytocin receptors have been found in organs unrelated to reproduction. Oxytocin is often referred to as the "love hormone" because of the role it plays in trust, generosity, friendship, attachment and bonding (Olff et. al., 2013).

There is evidence that administration of oxytocin improves social memory and enhances facial recognition (Rimmele, Hediger, Heinrichs, \& Klaver, 2009; Striepens, Kendrick, Maier, Hurlemann, 2011). The ability to read the emotional signals of others has been shown to 
increase with higher oxytocin levels (Domes, Heinrichs, Berger, \& Herpetz, 2007) which renders this hormone of benefit in socioemotional functioning. In autistic subjects, Andari, et. al., (2010) reported enhanced trust, improved reading of social cues and social interaction after oxytocin inhalation. Van Ijzendoorn \& Bakermans-Kraneburg, (2012) reported improved facial recognition and social cues.

Experiments have shown that the experience of empathy was associated with a $47 \%$ increase in oxytocin production (Barraza \& Zak, 2009). The response was stronger in females than in males but those males who received a dose of oxytocin were found to be much more adept, than the placebo group, at picking up emotional cues and identifying the mood and emotional signals from images of eyes (Domes et al., 2007). Not only have emotional empathy levels been shown to increase with oxytocin levels but also notable was a discernable increase in generosity toward strangers (Barraza \& Zak, 2009).

Caution must be used in the administration of oxytocin however. In animal studies, increasing doses of oxytocin have led to anti-social behaviours like jealousy and a tendency toward violent mate-guarding (Beery, 2002). The ambivalence of this neuropeptide makes its regulation difficult and its use in treating social deficits in humans may be precarious.

It is believed that sex-specific hormones (estrogen and testosterone) may affect the role of oxytocin, causing differences in empathic capacity between men and women, something that requires further study.

Estrogen, the primary purpose of which lies in the sexual development and function of the female body, is known to mediate the effects of testosterone and increase connectivity in areas of the brain associated with both cognitive and emotional processes (Ottowitz et al., 2008). In contrast to testosterone however, estrogen enhances greater emotional expressivity and 
In Praise of Empathy

empathic capacity due to its promoting the increased ability to recognize and identify facial expressions in others (Hampson, van Anders, \& Mullin, 2006; Kret \& De Gelder, 2012).

Olsson, Kopsida, Sorjonen, and Savij, (2016) found that when estrogen was administered to male subjects, there was an increase in emotional (vicarious) reactivity when observing others in distress.

Like testosterone, estrogen levels decline with advancing age (Ferrini \& Barrett-Connor, 1998). However lower empathy levels in most older females do not appear to be reported as a result of estrogen depletion but more as a result of cognitive decline which is variable according to heredity, positive outlook and the cohort effect.

Testosterone is well known for its important role in the development of male sexual attributes and reproductive tissues. The effects of testosterone on socioemotional behaviour have also been demonstrated. Experiments have revealed that a single dose of testosterone administered to young males suppressed facial mimicry in response to emotional facial expressions (Hermans, Putman, \& Van Honk, 2006).

While high testosterone levels in men are associated with lower levels of empathy, lowered levels of testosterone, due to a hormonal response, appear to increase their capacity for empathy (Montoya, Terburg, Bos, \& Van Honk, 2102). A study of fathers seeing their infants in distress after being separated from them, showed lowered testosterone levels as a result of their babies' anguish (Kuo et al., 2016).

In males, a drop in testosterone levels, usually associated with aging, often results in a reduction in libido, sexual dysfunction, fatigue, weight gain and cognitive decline. Less appreciated are the socioemotional changes that also occur when testosterone levels decline, some of which may actually be beneficial (Ebner, Kamin, Diaz, Cohen, \& MacDonald, 2015). 
Many men of advancing age are seen to express their softer skills more readily and often tear up in response to the emotional signals of others. Empathy in men is generally seen as an endearing quality, particularly from a female perspective. Interestingly, testosterone administered to young women reduced their capacity for empathy (Van Honk et. al., 2011). Under certain conditions, testosterone appears to negatively affect certain aspects of socioemotional functioning including the softer skills like empathy.

Cortisol, oxytocin, estrogen and testosterone may well be a significant part of the brain architecture that produces experienced empathy. No matter the disparities in empathic capacities found in experiments between males and females, empathy is a trait equally vital to both genders.

\section{People Who Are Empathic ...}

- Are active listeners.

- Are uncomfortable with prejudice and injustice.

- Feel and show real concern at cruelty, abuse, pain and unkindness.

- Are socially sensitive, inspire mass action and are more likely to become activists for social change.

- Develop ambitious imaginations - try to understand the world and its problems and get involved.

- Make good "ice breakers".

- Have an insatiable curiosity about strangers and often strike up conversations with people outside of their usual social group (Krznaric, 2014).

- Have richer social networks, volunteer more, donate more to charity and are more likely to help others (Gruhn, Rebucal, Diehl, Lumley, \& Labouvie-Vief, 2008). 
- Are able to step outside themselves to see and understand the perspective of others.

- Have a sense of self-awareness and the ability to identify and articulate their own feelings and distinguish them from the feelings of others.

- Recognise the feelings of others first, then try to determine the causes of a situation and take appropriate action.

- Try to separate the people from the problem to reveal shared experience and discover commonalities to dispel fear and distrust and to promote cooperation.

- Share in other people's joys and sorrows.

- Pay close attention to others' faces and body language.

- Are able to read the non-verbal cues of others (gestures, facial expressions, body language, tone of voice) and react appropriately.

- Often mirror the expressions of those with whom they are empathising (laugh when others laugh, yawn when others yawn, cry when others cry, tear up when others are distressed or elated and feel something happening inside themselves).

- Are less aggressive.

- Report higher life satisfaction, emotional intelligence, and self-esteem (Mayer, Salovey, \& Caruso, 2004) and strong interpersonal relationships.

- Report better mental health (lower stress, anxiety \& depression) and participate in fewer health risk behaviours such as smoking, drugs, alcohol consumption (Konrath \& Grynberg, 2016). 


\section{Empathy Versus Sympathy}

There has often been confusion over empathy vs sympathy. There are those who believe that when we think we are feeling empathy for someone whose suffering we have not experienced ourselves, what we are actually feeling is sympathy. Although they recognise that empathy is an affective as well as an intellectual virtue, these people feel that genuine empathy is not possible unless we, ourselves, have walked in someone else's shoes.

In a world without empathy, we would, presumably, still feel sympathy. Like empathy, sympathy is something we feel for someone else. But sympathy, because we have not felt something inside happening to $u s$, makes it easier for us, if we so choose, to walk away. Walking away from empathy however, is more difficult, perhaps because empathy is not only something we feel for others, but something that we experience inside ourselves, something that is also happening to $u s$. Another reason it is difficult for most of us to turn our backs on empathy is probably due to its inexorable link to conscience.

\section{Empathy ...}

- Is feeling with someone.

- Is an involuntary response.

- Is a true awareness and internalizing of how someone else is feeling.

- Is an innate ability to perceive and be sensitive to the emotional states of others.

- Is a gut reaction, an ache, a wave, a jolt, something felt by the observer in response to another's situation.

- Is emotional contagion.

- Is the antithesis of apathy, aggression and violence.

- Is the power to identify oneself mentally and physically with another. 
In Praise of Empathy

- Is understanding and vicariously experiencing the feelings of others.

- Is recognizing and internalizing someone else's suffering or their elation.

- Occurs in both sadness and in joy.

- Evokes sympathy, kindness and compassion, and moves us to act.

- Evokes feelings of joy and celebration.

- Is a shared experience.

- Is a deeper emotion than sympathy.

- Stirs conscience, moves us to be more tolerant and understanding.

- Can cause involuntary wincing at the sight of pain.

- Often involves involuntary mirroring the expressions of those we see in suffering or in joy.

- Sensitizes us to the perspectives of others

- Is crucial for the effective development of sympathy and compassion.

Sympathy ...

- Is feeling for someone.

- Is not an involuntary response.

- Is pity, commiseration, showing mercy.

- Is recognizing and acknowledging the feelings of another without actually feeling anything other than pity.

- Like empathy, evokes compassion.

- Does not occur under joyful circumstances.

- May cause wincing and/or mirroring the expressions of those we see in suffering although this is likely due to the empathy that we first experience. 
In comparing empathy, sympathy and compassion, we might ask ourselves...

Can empathy exist without sympathy and compassion? Only if we ignore it. This is difficult for empathic people because of the strong link between empathy and conscience. Empathy moves us to sympathy and compassion. Sympathy and compassion are the ensuing stages of care and concern.

Can sympathy exist without empathy? Probably - we may not have to actually feel for someone else in order to pity them.

Can sympathy exist without compassion? Yes, we can pity someone without taking action. Can compassion exist without empathy? No. Compassion is empathy with action where we are moved to help and resolve to make things better.

Can compassion exist without sympathy? Probably not - we need to feel pity for someone in order to be moved to show compassion. Sympathy inclines us to be merciful.

\section{Nurturing Empathy - The Moral Obligations of Parents, Teachers and Schools}

Ideally, the nurturing of empathy should begin in early childhood. Children develop emotional competence through the quality of the relationships they first develop with those closest to them. The kind of a start a child has in life determines her overall confidence, academic success, ability to cope with stress and to foster meaningful relationships with others.

Although empathy is inherent in each of us, we nurture it by demonstrating it for and toward our children so that they experience it firsthand. Once they see how it looks and come to understand how it feels to be on the receiving end, they are better able to show empathy for others. 
We all need to develop our ability to feel for others but in order to do this we need to be raised to understand, and freely express, our own concerns and emotions. It is difficult for a child to understand and relate to the emotions of others if he does not fully understand his own.

Nurturing empathy involves appropriate modelling, age appropriate conversations about feelings and helping children to recognize, understand and manage their own reasons for discomfort, hurt, anger, frustration, anxiety, elation, pride etc. This leads them to compassion (empathy with action) and to better understand the feelings of others in a variety of situations.

Parents, primary caregivers and teachers need to listen to children's hearts, to make sure they develop the emotional literacy necessary to help them describe how they feel, appropriately and effectively (Gordon, 2009). Children need help recognising why they feel a certain way and to have confidence that the adults around them hear and understand them. Suppression of, and negative attitudes toward, a child's expression of his emotions will stifle his empathy development (Wilkinson, in progress).

At an age-appropriate level, children must be given help to build and use emotional vocabulary, to engage in conversations about their own feelings and the feelings of others. Teaching moral principles and how our behaviour affects others is generally a good place to start (Hoffman \& Saltzein, 1967). Children need help and encouragement to read social and emotional cues, to imagine the perspectives of others, so that they are able to identify, understand and relate to a variety of emotions and viewpoints in other people and to distinguish them from their own emotions and perspectives. This deepens their empathic experience. They also need to learn to express their feelings appropriately and effectively. They need guidance to develop problem-solving skills, help with self-regulation and to learn how to soothe themselves and bounce back when they are upset, in order to develop the skills to soothe others. 
Nurturing empathy takes time. It should be continuous and schools must play a part. There can be no learning in an environment where there is fear and aggression (Wilkinson, 2017). A child suffering from anxiety, deep emotional pain, sadness and/or bullying, has no heart for learning. Schools have an important role to play in helping to raise moral, healthy children by fostering not only their cognitive development but also their social and emotional development. Apposite functioning of culture and civilization arises as a result of the embracing of socioemotional abilities (Adolphs, 2010). The teaching of these skills is central to reducing the incidence of bullying behaviour in schools (Durlak, Weissberg, Dymnicki, Taylor, \& Schellinger, 2011).

Schools that implement socioemotional learning, provide the foundation for creating a community of caring and compassion. The teaching of socioemotional skills, amongst other things, provides young people with the skills to cultivate, appreciate and demonstrate empathy, kindness and compassion. These are the tools they need to make connections with others, to foster healthy interpersonal relationships, to get along together and to be active members of the team they will almost certainly be a part of in their adult lives.

For children whose empathy has been stifled by adverse circumstances at home, it behoves schools to take up the slack if we are to raise, cooperatively, moral, caring and empathic citizens. The emotional and social life of students does not lie outside the jurisdiction of teachers (Gordon, 2009). They sometimes need to train the hearts of their students as well as their minds. The value of the softer skills like kindness, understanding, patience and acceptance must be deliberately taught and constantly reinforced. Lessons, not just about celebrating our differences but about how much we have in common, providing opportunities for teamwork and teaching the nature of our interdependence as members of one global family, are all helpful in 
developing empathy in children and enable them to see and understand the real benefits of working together peacefully and supportively, as a team, striving for common goals.

Early life experience and relationships exert an intense effect on our capacity for empathy. Children who have been subject to neglect and abuse are often distrustful and aggressive and come to believe, early in life, that their needs don't matter (Gordon, 2009), that adults cannot be trusted, that threats to their safety are all around them. It is next to impossible for a child who has not been raised in an empathic environment to understand, and therefore demonstrate, empathy.

We are all born with unique, innate, genetic components some of which may enhance or impede our ability to feel for others. One such component, often overlooked, is temperament. Temperament is genetic and influences, amongst other things, our activity level and how we respond to different situations. It exerts a profound effect on our capacity for empathy. Nature is not always fair. Some children are born contented, outgoing and focused. They come to school equipped with confidence, curiosity and a thirst for learning. Others are born fearful, easily distracted and even aggressive. They may arrive at school with more than their share of emotional baggage (Wilkinson, 2013). A cranky, restless child whose temperament makes it difficult for him to form friendships or to comply however, is not usually the result of poor parenting. Some children are simply more difficult to raise than others and require deeper understanding, guidance and more deliberate teaching of strategies for self- regulation and to appreciate the social norms for acceptable behaviour.

While we might make giant strides in teaching children the benefits of empathy and how to maximize our potential for it, parents, primary caregivers and teachers need to understand the role that temperament plays in behaviour and responses. Nurturing empathy and the teaching 
and learning of prosocial behaviours can therefore sometimes be difficult. Child rearing and teaching requires profound patience and understanding on the part of parents, primary caregivers and teachers who may, themselves, need additional support for strategies with these children.

All good teachers build on whatever foundation a child brings to school. They are fully aware of the myriad ways in which children learn and are creative in their approach to teaching by explaining concepts in a variety of ways in order to engage and accommodate everyone in their classrooms. A tall order indeed, but it can be done and the extra effort this takes often yields rewarding results and a variety of teachable moments which satisfy even the most restless, difficult and easily-distracted learner.

Schools, in general, must also provide support for struggling parents and on-the-job support for both new and seasoned teachers who feel they need it. Their classrooms are safe havens for many students living in adversity. How teachers relate to their students is of utmost importance; they, like parents, have the power to shape young lives.

But merely nurturing and teaching empathy is of little use and less likely to stick, unless children are taught to appreciate the real value and benefits of empathy, in particular the important part they, themselves, can play in reducing aggression and unkindness in their environment and the friendships and teamwork that flourish as a result. They also need opportunities to put empathy into practice if it is to become a habit. Once children begin to understand and experience empathy, they come to believe in it.

Peer pressure in schools can sometimes cause empathy to evaporate. Some children may be persuaded to believe that hanging out with those who are different from themselves, including children from a different race or disabled children for example, is uncool. Schools also have a moral obligation to teach acceptance and to dispel the stigma around disabilities, in particular 
those that are invisible, and other mental health issues.

Herein lies a teachable moment! Including disability and mental health as part of the general health curriculum (Lauria-Horner, Kutcher, \& Brooks, 2004), would increase the understanding of all children, dispel any associated stigma, quell peer resentment and enhance empathy, compassion and acceptance amongst students. In other words, it would give real meaning to what all schools purport to provide - 'an inclusive environment' (Wilkinson, 2017).

As they grow, children need to understand and celebrate diversity, to appreciate that people who may appear and act differently from themselves have value and deserve our attention, respect and compassion. They need to be taught the real benefits of teamwork and the nature of our interdependence as a global family (Wilkinson, 2017). By modelling the many facets of empathy for children every day, we lead them to become understanding and caring, more sensitive to the feelings and needs of others and they will, most likely, carry their gift of empathy into adulthood.

Empathy training enhances both critical and creative thinking as well as insight, and the ability to solve problems (Gallo, 1989). Children involved in empathy training have been shown to develop higher- order reading comprehension (Kohn, 1991).

Empathy may also be deliberately induced at any age where there is an empathy deficit and generally involves the use of prompts and role play, modelling and reinforcement, showing examples of sympathy, laughing at absurdities, celebrating the success of others, cultivating active listening and learning to identify, and to talk about, feelings in ourselves and others.

Inducing empathy in autistic children and youth has generated positive results (Gena, Krantz, McLannahan, \& Poulson, 1996; Reeve, Reeve, Townsend, \& Poulson, 2007) even in autistic children as young as 4 years (Schrandt, Buffington-Townsend, \& Poulson, 2009). 
Empathy training has also proved to be a useful tool in awakening empathy in children with oppositional defiant and narcissistic personality disorders - conditions which are also known to be characterized by empathy deficiencies (Blair, 1999; Bons et. al., 2013; Klapwijck et. al., 2016).

Techniques for nurturing empathy are also used in the treatment of people with posttraumatic stress disorder (PTSD) (Wilson \& Thomas, 2004) and in debriefing those who have been radicalized. Because empathy is intrinsic in each one of us, whether it has been nurtured and is therefore active or whether it has been neutralized by negative experience and lies dormant inside us, it can be invigorated, restored, reawakened, taught.

The links between empathy, anxiety and relational aggression are strong. Those with high levels of anxiety tend to be less empathic and more relationally aggressive than their peers (Loudin, Loukas, \& Robinson, 2003). Teaching empathy has a beneficial effect on relieving anxiety and therefore reduces relational aggression by leading people to step outside themselves to consider the plight of others. Empathy has been shown to inhibit aggression and other antisocial behaviours like bullying (Batson et. al., 2004; Jolliffe \& Farrington, 2006) and there is consistent evidence that empathy training mitigates specific types of aggression in which empathy is implicated (abuse, sexual harassment and victim blaming) (Schewe, 2007; Schewe \& O’Donohue, 1993).

Relational aggression is common in cyberbullying. Steffgen, Konig, Pfetsch and Meltzer, (2011), studied the relationship between cyberbullying behaviour and empathy. As was hypothesized, those who indulged in cyberbullying demonstrated less empathic responsiveness and more relational aggression than those who had never bullied. The formal training of empathy skills is an important tool in decreasing the incidence of cyberbullying (Wilkinson, 2017). 
Empathy training and anti-bullying programs that teach children how to read social cues and take another's perspective, having subjects put themselves in someone else's shoes, do have an inhibiting effect on aggression, particularly in children (Schonert-Reichl, Smith, Zaidman, \& Hertzman, 2012). Age-appropriate training also appears to reduce prejudice for those who are often stigmatized due to differences in age, gender, ability, strength, level of intelligence, race, sexual orientation, economic status, family circumstances, gender, ethnicity and culture, skin colour, religion/beliefs, dress choice and personality (Wilkinson, 2017).

\section{The Roots of Empathy}

Along with Socioemotional Learning, probably the most effective program for teaching, eliciting and perpetuating empathy in children and youth today, is The Roots of Empathy (ROE) (Gordon, 2009). This program is undoubtedly the single most effective prosocial, bullying prevention program available to all schools across the world. The Roots of Empathy teaches emotional literacy and the nature of our shared humanity. There are lessons about understanding emotions, ours and those of others, perspective taking, caring and infant development. The Roots of Empathy also addresses the root cause of bullying - an empathy deficit.

The brainchild of Canadian award-winning social entrepreneur, educator, author, child advocate and parenting expert, Mary Gordon, this program is presented in schools worldwide, by trained, certified instructors, to children from kindergarten to grade 8 . Children follow the life of a baby (brought into the classrooms by volunteer mothers). They learn about the baby's special needs and reliance on others for healthy growth, emotional and physical. Since the baby cannot voice its concerns and needs in the early days, children must learn to read its facial expressions and body language. They learn to step outside themselves and to put themselves in the infant's 
shoes. They are encouraged to develop their emotional intelligence and grow their emotional vocabulary by talking about how they imagine life must be for a baby at every stage of its development.

Story-telling plays a large part in ROE and offers opportunities for children to identify and express their own feelings as they observe the baby and share its frustrations in its effort to communicate its needs. They come to discover commonalities with their classmates which brings them closer together so that classroom dynamics are enhanced. Teachers have reported heightened insight into the thoughts and feelings of their students as they observed the students' responses to the baby's needs and aggravations during the visits. They felt better equipped to respond to the wide variety of emotions in their students that confront them on a daily basis, moving them to pay more attention to the underlying feelings that lead to certain behaviours in the classroom.

There are multiple links between ROE and the school curriculum with implications for health, music, art, math, social studies and language arts. Appropriate literature is selected for reading alongside the program.

ROE is not only good for the hearts of children, the improvement of behaviour in every area and in general classroom dynamics, but also supremely suitable for raising awareness of the empathy deficit in today's world. The program also provides support for struggling parents and increases their awareness and understanding of the needs of their babies and the nature of our interdependence as a family, a school, a city, a country and the world (Wilkinson, 2017).

There is strong empirical evidence that this program decreases aggression and raises empathy levels in children (Schonert-Reichl, Smith, Zaidman-Zait, \& Hertzman, 2012). Reduced incidence of bullying has been reported in schools where the program was presented. 
In Praise of Empathy

Interpersonal relationships and resilience were greatly improved and children, many of whom were not raised in empathic environments, became more caring and supportive of each other and less likely to exclude those who are different from themselves.

Perhaps every parent should read the book "The Roots of Empathy" and it might well become required reading for every teacher and school principal. It is a comprehensive guide to the development of empathy in children and an explanation of the program available to schools. It would be well to have this program made mandatory as part of all school health programs.

\section{Empathy Games}

Growing in popularity in schools, is a number of video games that purport to promote empathy in game players. Video games have long suffered stigma due to their violent origins, but some new games are based on true stories and situations from across the world and are different from books and movies in that they place the players in the centre of the action where they are able to "live" the experience of the characters in conditions of war, poverty, and other forms of adversity. These games differ from most other video games inasmuch as the player, instead of taking the part of the soldier or super hero, is a civilian, a bystander, in a modern-day conflict zone.

Like most video games, the empathy games are interactive and there are opportunities for decision making and risk-taking and players are left to deal with the consequences of their actions. Players are brought into the reality of a situation. They come to understand the challenges presented and how it feels to be caught up in war for example, not knowing where their families are or what disaster tomorrow may bring. They are encouraged to take a "focused empathic posture" (Belman \& Flanagan, 2010), to deal with the conflict analytically, to explore 
ways in which their interaction may affect the outcome and to consider the feelings of the other characters in the game and how they will be affected by the decisions they make. They find themselves responsible for the welfare and safety of others. Just as in conflict resolution training, players are encouraged to separate the people from the problem and to seek out and identify shared needs.

These video games are currently receiving major endorsements from UNESCO which commissioned a paper recently on how gaming can help with conflict resolution (Darvasi, 2016) and which is producing its own video game "World Rescue". It is thought that these games are an appropriate vehicle for cultivating perspective in young people, for their potential to create a profound psychological, emotional and cognitive resonance in players and possibly to leave a strong imprint.

Researchers out of the University of Wisconsin, U.S.A., also developed a video game to promote empathy in youth. Initial findings suggest that the games produced behaviourallyrelevant functional neural changes after less than six hours of game play (Krai et al., 2018).

The efficacy of empathy games is difficult to determine at this point - the idea is new, and the games have their share of skeptics. It is believed that, since most young people play video games to "win" or "succeed" at all costs, priming of the players with a short video or a talk about empathy before proceeding with the games, is more likely to help achieve the desired outcome (promoting empathy).

Caution is also required since hours in front of a screen have been shown to exert a damaging effect on the developing brain and, amongst the myriad negative effects on both physical and mental health, interfere with the emergence of empathy (Sigman, 2012; Wilkinson, in progress). 
In Praise of Empathy

\section{The Nay-Sayers}

Paul Bloom, Professor of Psychology and Cognitive Science at Yale University, and Jesse Prinz, Professor of Philosophy and Director of the Committee for Interdisciplinary Science Studies at the Graduate Center of the City University of New York, each look at empathy through a cynical lens. Bloom's book, “Against Empathy: The Case for Rational Compassion” (2016) has sparked a great deal of controversy and prompted public talks, presentations and series on the benefits and possible drawbacks and risks of empathy.

Bloom believes empathy to be destructive, corrosive and too emotional, so that people who experience it become worn out, leaving them blind to larger scale problems in the world and with little or no energy to respond appropriately. He states that empathy stirs up emotions and emotion clouds vision and gets in the way of rational decision making.

Since empathy motivates more sensitive caregiving in the "caring" professions, it is true that empathic over-arousal is a common condition in professions such as social work, medicine and in first line responders (police, fire, ambulance, crisis teams etc.). Also known as “compassion fatigue" (Figley, 1995) or "burnout", this condition is described as an experience of "stress resulting from helping, or wanting to help, a traumatized or suffering person" (Bride, 2007; Tehrani, 2010).

But empathy, by its very nature, is an immediate, emotional response and while we should, perhaps, try to avoid compassion fatigue, it is important to note that this more usually occurs in people who witness the suffering of others on a daily basis as a result of their professions. We should not lose sight of the fact that emotions are mechanisms for survival and communication. Emotion, if we allow it to, drives most of us to affirmative action, to the great benefit of others. 
And if it is true that our empathy for a single human being blinds us to greater world problems, how do we explain the massive public outpouring in response to world disasters like earthquakes, tornados, floods, forest fires, tsunamis and the refugee crisis? Amnesty International mobilises thousands of people (who have never experienced torture or imprisonment as a result of their beliefs) to take action on behalf of those who have. Such is the power of human empathy to save lives, to inspire, to encourage and to facilitate change.

There is no hard evidence to prove that when we demonstrate empathy for a small child for example, we are blinded to the greater problems of the world. There is little doubt that empathic people remain fully aware of the world's intractable problems. It may be argued that when our empathy moves us to do our part in mitigating difficulties on a smaller scale, we are attending to situations we believe we have the power to change, circumstances over which we feel, as individuals, we might have the ability to attenuate or control. Is it better to do nothing, to sit back, to lament and contemplate the world's problems or to take on what we believe we can handle, to make a difference within our reach, to one vulnerable person at a time?

Both Bloom and Prinz point to the biased nature of empathy. Prinz, in his paper "Against Empathy" (2011: 227), writes about the "similarity bias" where empathy is often reserved for those who are similar to ourselves. Both believe that we reserve empathy for our own group, people who look like us and small children in distress and that the cases that capture our attention and concern are "adorable children in trouble". In his interview on CBC Radio's "The Current" (January 4, 2017), Bloom, in his discussion of bias, said, "We ask, 'who's got the best face?', 'who's making me cry?"'

As much as we might like to believe otherwise, it is true that empathy does, in fact, discriminate! Situational factors and individual motives come into play and affect how we 
In Praise of Empathy

integrate the components of empathy in order to understand and interact with others and with the world in general (Zaki, 2014). This is more than just a theory. There is evidence that while, as caring members of society, we may try hard not to discriminate, we are, in fact, more likely to empathise amongst our own social groups, with others to whom we may relate, than with outsiders (Batson, Turk, Shaw, \& Klein, 1995; Krebs, 1975) and, not surprisingly, toward those with whom we share emotional closeness (Beeney, Franklin, Levy, \& Adams, 2011).

Infants, in particular, have been found to evoke more empathy than adults (Batson, Lishner, Cook, \& Sawyer, 2005; Preston, 2013) as are those considered attractive (Muller, Leeuwen, Baaren, Bekkering, \& Dijksterhuis, 2013) and/or vulnerable. Within our immediate family and among our closest friends, the empathy portal is almost always turned on. But empathic people find it very difficult to turn away from anyone's distress, family, friend or even a stranger, which may well be related to empathy's inseparable relationship with conscience.

Empirical evidence for the biased nature of empathy includes an experiment conducted by Meyer et. al. (2013). Functional MRI was employed to determine whether or not the same brain mechanisms respond when people observe the social exclusion of both friends and strangers. While it was clear that the subjects did, in fact, feel empathy for both friends and strangers, different areas of their brains were activated.

Functional MRI showed that affective pain regions of the brain were activated when subjects observed the social exclusion of friends (emotional empathy). When they observed the same plight in strangers however, the brain regions activated were those associated with mentalizing, i.e. thinking about the traits, mental states and intentions of others (cognitive empathy) rather than actually sharing their experience/feeling their pain. However, if empathy directs us first to favour our own group, does that mean we ignore the plight of strangers? 
Apparently not. It would appear that we still feel and demonstrate empathy for people of all ages and cultures, even those who are not known to us, but in a different form.

Bloom insists that we are blind to the consequences of our actions, that empathy makes us step away from rationality, from things that would make the world a better place. He believes that rational compassion makes us work harder at recognising what is morally right, that we must always stop to look at the facts. He suggests that we ignore our empathic response and advises us to distance ourselves, to step back, so that rather than suffering vicariously, we should take time to consider the situation and make more rational decisions that have the potential to really help. We should ask ourselves, "What'll make most people happy, what'1l make the world a better place?" But if we step back, time is lost, and to whom do we direct our attention first?

Bloom also believes that the best people to help are those who care about others but don't feel their pain. What he is actually considering here is sympathy. Certainly, those in distress will benefit from the sympathy of others but it seems probable that care administered to those in need would be more appropriate and effective if those who dispensed it had a deepened perception and understanding of their emotional state.

More than once, Paul Bloom does concede that an empathic appeal can make the world a better place but adds that he can point to a dozen instances where empathy has led to mistakes. He worries about the connection between empathy and war and hints at its vulnerability, how it can easily be degraded and subverted and used to promote hatred.

He also believes that there exists a punitive response provoked in people as a result of their empathy and that people may be moved toward a desire for revenge. He feels that our reaction to the suffering we see sometimes moves us to want to make the person responsible pay, 
that empathy tilts the scale too much in favour of violence and moves us to strike back.

While there may be a small sector of society that feels this way, it is difficult to imagine that empathy, itself, elicits a punitive response in most people. However, it is true that empathy, like love, is vulnerable to subversion. Populist leaders, like Donald Trump, exploit empathy by evoking it for victims of crimes committed by immigrants. In this way, they not only use empathy to promote hatred but also prompt people to seek revenge. As abhorrent as this is, empathy is likely not the culprit here, but rather the way it is corrupted and subverted, the way it is used!

In his defence, there is little doubt that Professor Bloom wants to help make the world a better place. While more rational compassion might be a good thing, replacing empathy with rational compassion would surely be a mistake. He ignores, completely, the fact that empathy is a precursor to compassion. His message: “Don’t listen to your heart, listen to your head instead". But what if that head is full of prejudice, hatred and intolerance? This is a precarious thought especially when we consider government decision making in rogue states.

Despite the title of his book, it is possible that Paul Bloom is not, in fact, against empathy per se but rather the knee jerk reaction that empathy often elicits, its vulnerability to subversion and what he believes to be its link to a punitive response.

Simon Baron-Cohen (2011) believes that there are serious dangers in leaving empathy out of our decision making. For one thing, compassion is fed by empathy. Empathy evokes compassion. Allowing our empathy to be stifled, would result in a diluted form of compassion. Perhaps what the world needs is not less empathy but simply more rational compassion. With the alarming rise of populist mentality and the pervasive rhetoric that persuades us to move away from the softer skills like patience, kindness, tolerance, understanding and acceptance, we 
might not be at all surprised to find that empathy is also currently on the chopping block.

\section{The Empathy Deficit in Today's World}

Contrary to the beliefs of Professors Bloom, Prinz and others, many people believe there is a dearth of empathy in the world today. The empathy deficit and its repercussions are perhaps most apparent in the news and on the internet. Fear and prejudice remain prevalent impediments to societal growth. Hate sites spring up everywhere across the world at an alarming rate and we are not exempt from their influence no matter where we live. Extreme right, white supremacist groups like Neo Nazis, the Alt-Right movement, Sons of Odin and many other radical organizations, use the internet to instill fear and suspicion and to perpetuate their causes and disseminate messages of hate.

The anonymity of the internet has brought out the very worst traits in human nature and not just in radical extremists but in ordinary people who post hateful, insulting and damaging slurs and narrative online that many of them would likely never articulate in public. Social networking and the sending of hate mail, blocks out any opportunity for empathy since those online cannot see the faces, hear nuances in voice tone or read the body language of the people they malign (Wilkinson, in progress).

The populace is increasingly encouraged, of course, by extreme, right-wing, populist leaders who are brought to power by disenfranchised, disenchanted, discontented bodies of resentful people who are simply anxious for a change to the status quo. These people are angry and vulnerable, perfect fodder for those who would corrupt and subvert them. They are encouraged, even given permission it seems, by their elected, sometimes racist, misogynistic officials, to express, freely, their anger and their hate, in public and online. It is clear that these 
In Praise of Empathy

unfortunate individuals, as well as those who belong to radical groups, suffer from an empathy deficit. They have no capacity to imagine or consider the pain of others and don't stop to think of the damaging effects and potentially fatal consequences of their behaviour.

Empathy disorders can have a profound effect on our conduct and our actions. Empathy deficits often result in hate crimes like exclusion, bullying, aggression, racism, violence and genocide. They show up in the perpetrators of physical and psychological violence and the atrocities they commit and which we see and hear about every day, at home and abroad; inhumane atrocities that empathic people find too horrifying to contemplate. Not only do barbaric actions of torture and killing violate our sensibilities, but, if we are empathic, images of the resulting human suffering cause us, as witnesses, a significant degree of personal physical and psychological pain.

Deficits in empathic processes cause impaired social cognition which leads to difficulties with social interaction. People with empathy deficits, both adults and children, have particular difficulty simply getting along with others and, more importantly, forging appropriate and meaningful friendships. We must be cautious in our discussion of empathy deficits however, as Professor Bloom (2016) reminds us. It is important that we consider the fact that while those who commit crimes against humanity are known to have low empathy, not all who have empathy deficits are violent or aggressive. People on the autism spectrum with low empathy, who may have difficulties reading social cues and relating to others, generally show no propensity for violence, exploitation or aggression. These people frequently have high moral codes and are more likely to become victims of aggression than perpetrators.

Empathy deficits are common in those who suffer from PTSD who have been exposed, over long periods, to a steady diet of violence and human suffering. They become desensitized 
as a result. Terrorist groups use repeated disturbing images and real-life violence to neutralize empathy in their new recruits - this is part of radicalization. They realize that empathy stands in the way of violent behaviour. Low empathy can lead to less concern about harming others (Joliffe \& Farrington, 2004, 2006).

Over the last 30 years, researchers have reported a decline in empathy in young people in the USA (Konrath, O'Brien, \& Hsing, 2011) while, interestingly, scores on the Narcissistic Personality Inventory (which assesses high self focus in the "Me" generation) have increased across the same time period (Twenge, Konrath, Foster, Campbell, \& Bushman, 2008). One of the hallmarks of narcissistic personality disorder is low empathy.

There is also a distinct lack of empathy apparent in government decision-making across the world. It is not just negative actions that contribute to the empathy deficit, but apathy! In the developed world, we hear, constantly, about the need to do more for the middle class yet there are few initiatives to help the poor, the homeless and jobless and, consequently, the disenfranchised and marginalised. Empathy-driven government resolutions to address world poverty, for example, would not only constitute the greatest global humanitarian initiative ever made but would save governments billions of dollars in healthcare expenditures and in spending on the criminal justice system (Wilkinson, 2017).

Although some of the factors that contribute to the empathy deficit have been discussed (temperament, adverse childhood experience including poverty, inequality, neglect, lack of nurturing, gender-specific parenting, hormonal imbalance and populist rhetoric), the complete list of impediments to the healthy development of empathy is long and worthy of greater examination beyond the scope of this paper. Other barriers include attachment disruption, substance abuse, disconnection, poor role models, learned prejudice, affluence and largesse, 
In Praise of Empathy

power parenting (Unger, 2009), touch deprivation (Field, 2014), narcissism (Twenge, 2009)

and technology (excessive screen-time - phones, computers, video games and television, social media and hate music).

"Empathy helps us to find our moral compass in a world where we are at risk of being anaesthetized by sensory information overload.” Mary Gordon (2007: 127).

\section{Discussion}

It is difficult for empathic people to imagine a world without empathy. What a dangerous, unfeeling place it would be. A world without empathy would be a world without emotion and compassion; a sad, isolating and violent place devoid of care, in which no one would feel safe, and in an even greater state of chaos and suffering than it is now.

Empathy, by its very nature, leads to increased trust, forgiveness and support (Crocker \& Canevello, 2008) and enhances attachment and interpersonal relationships (Paleari, Regalia, \& Fincham, 2005; Thomas \& Fletcher, 2003). According to Morelli et al. (2014), "Empathy heightens our focus and concern for others regardless of what specific emotion the target is experiencing and motivates us to behave socially".

Humans are hard-wired to experience the pain and elation of others. We have an inherent desire to understand and to help one another cooperatively and to socialize. Socioemotional processing, related to our ability to care and cooperate, share ideas and develop morality, are what many believe separate us from other species.

However, De Waal (2014), has demonstrated, along with human traits like aggression, selfishness and the desire for dominance, cooperation, reconciliation, concern, consolation, reciprocity, compassion and what appears to be empathy in experiments with certain animals 
including apes, elephants and dogs. Birds also appear to show signs of concern for each other by sending out signals of a food source as well as warning calls when their young are in trouble and when a predator is near (Gill \& Bierema, 2013).

Although empathy is inherent in each of us, it must be continually nourished and nurtured in childhood in order to become a way of life as our children grow. While all good parents model empathy in the home, learning the value and true benefits of empathy is the best way to ensure it becomes a habit. As primary caregivers, we need to help each child to develop a moral compass and create opportunities for our children both to witness empathy and to employ it. If we are to instil in our children any sense of human decency and awaken their capacity for kindness and compassion, it behoves each of us to teach emotional literacy, to be a role model, to preserve and perpetuate the gift of empathy and to allow our children to see the enormous benefits of living in a world where kindness and cooperation thrive.

Schools also have an important role to play - parents must press for the teaching of socioemotional skills. Teachers must provide children with constant reminders of our shared humanity and the nature of our interdependence in order to build rapport and strong connections with each other. They can help their students to become emotionally literate, to build a 'feelings' vocabulary and to learn to identify their own emotions in order to relate to the emotions of others. Children need to practise, continually, prosocial skills, and to put their abilities to share with, and care about, their peers into practice. Schools need to set the stage to build emotional contagion (so that children see empathy in action and "catch" it) as well as providing frequent opportunities for teamwork and cooperation.

Higher levels of empathy and cooperation in those working in internal medicine have been shown to result in personal feelings of increased mental wellbeing (Shanafelt et. al., 2005). 
There also exists a robust volume of literature concerned with the importance of empathy in the caring professions such as medicine, psychology, social work and teaching. Empathic professionals who work in these disciplines have been shown to exert a positive influence on those in their care (Beck, Daughtridge, \& Sloane, 2002; Derksen, Bensing, \& Lagro-Janssen, 2013; Goldman, 2018).

World communities survive by a system of give and take, by sharing with and caring for each other. Nations must strive to communicate, cooperate and to build strong relationships with each other. Since empathy is crucial in fostering meaningful connections, we need to value and preserve it if our goal is to lead happy, peaceful, productive and fulfilling lives as members of an interdependent global family. Our emotions are mechanisms for survival and communication. When communication fails and we cease to care for others, we become isolated, lost and without purpose.

Making and keeping friends is arguably one of the most important keys to happiness in life. Learning to get along together whether nurturing family ties, building relationships with school friends, cooperating in the workplace or volunteering on a team to make a difference, is crucial for successful, happy and peaceful coexistence. Aside from benefits to our physical and mental health, forming meaningful relationships with others provides enormous benefits to ourselves and to those around us in terms of emotional, and spiritual well-being.

We may choose to ignore our capacity for empathy or to apply it to the benefit of those around us. Thankfully, most people tend to reach out to each other and take up the burdens of those in need but our responses to those needs are, in fact, unique and shaped by our culture and by our experience of the world. Although fear and biases toward others remain predominant impediments to our attaining the highest level of societal growth and progress, humanity seems 
to be evolutionarily motivated and driven to overcome these problems thanks to the development of brain pathways (Feldman-Barrett, 2017) that lead us to empathy.

To replace empathy by practical ways of well-thought-out compassion, as Bloom suggests, implies that we should take our time to plan. Sometimes people in need of help are already out of time. While there may be a strong case for more rational compassion it must not be at the expense of empathy.

Empathy is a gift and a gift is worthless unless it is put to good use, shared or given away. Most of us recognise our gift of empathy and, with time and age-appropriate guidance, children will also come to acknowledge it, to trust it and to allow it to guide the way they respond to others. We need to open the floodgates, express our empathy and allow it to lead us, naturally, to compassion in the interests of those around us. Empathy invokes compassion and any kind of compassion, in the absence of empathy (if it can exist at all) is anaemic.

Unless our lives are marked by mutual kindness and respect, time taken to understand each other, we miss opportunities to enjoy the ensuing sense of common duty and common interests which arise when we work together as a team for the common good. Without taking time to understand each other, our lives have less meaning, there arises ignorance, misunderstanding, prejudice, racism, fear, conflicting perspectives, resentment and sometimes even violence.

We need to make space for empathy in the world rather than plan for a decision-making system without it. And since empathy is a default setting for most of us, an emotional but involuntary and automatic response, it's not likely that we could do away with it even if we wanted to. The ability to perceive others' intentions and emotions and to learn from their experiences are critical to the survival of our humanity. 
In Praise of Empathy

No matter its genesis, empathy is intrinsic in each of us whether it is alive or dormant, whether it has been nurtured or neutralized. Some people may choose, or be persuaded, to ignore it; hopefully, the rest of us will listen to our hearts, hear our inner voices, respond to that knee jerk reaction and allow it to move us to compassion. To call upon our inborn capacity to feel for one another, can only be to any society's advantage. Empathy makes the world a better, kinder place.

Dedication: This paper is dedicated to my parents, Cyril and Peggy Gregory, whose resilience in the face of personal tragedy and ability to allow love, warmth, empathy, compassion, gratitude, and even laughter, to transcend their pain, has been an enduring example that will live on in the lives of their children and grandchildren. I am also indebted to Geoffrey Landen-Turner, a gifted teacher who imbued in me an insatiable thirst for knowledge and the passion to strive for excellence. 


\section{References}

Adolphs, R. (2010). What does the amygdala contribute to social cognition? Annals of the New York Academy of Sciences, 1191(1), 42-61.

Andari, E., Duhamel, J-R., Zalla, T., Herbrecht, E., Leboyer, M., \& Sirigu, A. (2010). Promoting social behavior with oxytocin in high functioning autism spectrum disorders. National Academy of Sciences of the United States of America, 107(9), 4389-4394.

Baron-Cohen, S. (2002). The extreme male brain theory of autism. Trends in Cognitive Sciences, 6, 248-254.

Baron- Cohen, S., Richler, J. Bisarya, D, Gurunathan, N., \& Wheelwright, S. (2004). The systemizing quotient: An investigation of adults with Aspergher syndrome or highfunctioning autism, and normal sex differences. In U. Frith, \& E. L. Hill (Eds.), Autism: Mind and Brain (pp. 161-186). Oxford, England: Oxford University Press.

Baron-Cohen, S. (2011). The Science of Evil: On empathy and the origins of cruelty. New York, NY: Basic Books.

Barraza, J. A., \& Zak, P. J. (2009). Empathy toward strangers triggers oxytocin release and subsequent generosity. Annals of the New York Academy of Science, 1167, 182-189.

Bartz, J., Zaki, J., Bolger, N., Hollander, E., Ludwig, N. N., Kolevzon, A., \& Ochsner, K.N. (2010). Oxytocin selectively improves empathic accuracy. Psychological Science, 21(10), 1426-1428.

Batson, C. D. (1990). Self-report ratings of empathic emotion. In N. Eisenberg, \& J. Strayer (Eds.), Empathy and its Development (pp. 356-360). New York, NY: Cambridge University Press.

Batson, C.D., (2011). Altruism in Humans. Oxford, UK: Oxford University Press.

Batson, C. D., Ahmad, N., \& Stocks, E. (2004). Benefits and liabilities of empathy-induced altruism, in A.G. Miller (Ed.), The Social Psychology of Good and Evil (pp.359-385). New York, NY: Guilford Press.

Batson, C. D., Chang, J., Orr, R., \& Rowland, J. (2002). Empathy, Attitudes, and Action: Can feeling for a member of a stigmatized group motivate one to help the group? Personality and Social Psychology Bulletin, 28(12), 1656-1666.

Batson, C. D., Lishner, D. A., Cook, J., \& Sawyer, S. (2005). Similarity and nurturance: Two possible sources of empathy for strangers. Basic and Applied Social Psychology, 27(1), $15-25$. 
Batson, C. D., Turk, C. L., Shaw, L. L., \& Klein, T. R. (1995). Information function of empathic emotion: Learning that we value the other's welfare. Journal of Personality and Social Psychology, 68(2), 300.

Beck, R. S., Daughtridge, R., \& Sloane, P. D. (2002). Physician-patient communication in the primary care office: a systematic review. The Journal of the American Board of Family Practice, 15(1), 25-38.

Beeney, J. E., Franklin Jr, R. G., Levy, K. N., \& Adams Jr, R. B. (2011). I feel your pain: emotional closeness modulates neural responses to empathically experienced rejection. Social Neuroscience, 6(4), 369-376.

Beery, A.K. (2015). Antisocial oxytocin: complex effects on social behavior. Current Opinion in Behavioral Sciences, 6, 174-182.

Belman, J., \& Flanagan, M. (2010). Designing games to foster empathy. Cognitive Technology, $14(2), 5-15$.

Blair, R. J. R. (1999). Responsiveness to distress cues in the child with psychopathic tendencies. Personality and Individual Differences, 27(1), 135-145.

Bloom, P. (2017). Against empathy [Audio podcast]. Retrieved from http://www.cbc.ca/radio/popup/audio/listen.html?autoPlay=true\&mediaIds=847323715 $\underline{769}$

Bloom, P. (2016). Against Empathy: The case for rational compassion. New York, NY: Harper-Collins.

Bons, D., van den Broek, E., Scheepers, F., Herpers, P., Rommelse, N., \& Buitelaaar, J. K. (2013). Motor, Emotional, and Cognitive Empathy in Children and Adolescents with Autism Spectrum Disorder and Conduct Disorder. Journal of Abnormal Child Psychology, 41(3), 425-443.

Booth, A., Granger, D.A., \& Shirtcliff, E.A. (2008). Gender- and age-related differences in the association between social relationship quality and trait levels of salivary cortisol. Journal of Research on Adolescence, 18(2), 239-260.

Borba, M. (2001). Building Moral Intelligence: The Seven Essential Virtues That Teach Kids to Do the Right Thing. San Francisco, CA: Jossey-Bass.

Borke, H. (1971). Interpersonal Perception of Young Children: Egocentrism or Empathy? Developmental Psychology, 5(2), 263-269.

Bride, B. E. (2007). Prevalence of secondary traumatic stress among social workers. Social Work, 52(1), 63-70. 
Brody, L.H., \& Hall, J. (1993). Gender and Emotion. In M. Lewis, \& J. Haviland (Eds.), Handbook of Emotions (pp.447-460). New York, NY: Guildford Press.

Cappola, A. R., Maggio M., \& Ferrucci, L. (2008). Is research on hormones and aging finished? No! Just started! Journal of Gerontology. Series A, Biological Sciences \& Medical Sciences, 63, 696-698

Cardoso, C., Ellenbogen, M. A., Orlando, M. A., Bacon, S. L., \& Joober, R. (2013). Intranasal oxytocin attenuates the cortisol response to physical stress: A dose-response study. Psychoneuroendocrinology, 38(3), 399-407.

Carter, C. S. (1992). Oxytocin and sexual behavior. Neuroscience \& Biobehavioral Reviews, 16(2), 131-144.

Carter, C. S. (1998). Neuroendocrine perspectives on social attachment and love. Psychoneuroendocrinology, 23, 779-818.

Clodi, M., Vila, G., Geyeregger, R., Riedl, M., Stulnig, T. M., Struck, J., ...Luger, A. (2008). Oxytocin alleviates the neuroendocrine and cytokine response to bacterial endotoxin in healthy men. American Journal of Physiology-Endocrinology and Metabolism, 295(3), E686-E691.

Crocker, J., \& Canevello, A. (2008). Creating and undermining social support in communal relationships: The role of compassionate and self-image goals. Journal of Personality and Social Psychology, 95(3), 555-575.

Darvasi, P. (2016). Empathy, Perspective and Complicity: How digital games can support peace, education and conflict resolution. Commissioned by United Nations Educational, Scientific and Cultural Organization and Mahatma Ghandi Institute of Education for Peace and Sustainable Development. Retrieved, March 2017, from: http://mgiep.unesco.org/wp-content/uploads/2016/12/WORKING-PAPER-PAULDARVASI-.pdf

Dawes, C.T., Loewen, P.J, Schreiber, D., Simmons, A.N., Flagan, T., McElreath, R., ...Paulus, M.P. (2012). Neural basis of egalitarian behavior. Proceedings of the National Academy of Sciences of the United States of America, 109, 6479-6483.

De Waal, F. (2009). The Age of Empathy: Nature's Lessons for a Kinder Society. New York, NY: Three Rivers Press (Random House).

De Waal, F. (2014, March). Do animals have morals? [Video file]. Retrieved from https://www.ted.com/talks/frans_de_waal_do_animals_have_morals

Decety, J., Michalska, K., \& Akitsuki, Y. (2008a). Who caused the pain? An fMRI investigation of empathy and intentionality in children. Neuropsychologia, 46(11), 2607-2614. 
Derksen, F., Bensing, J., \& Lagro-Janssen, A. (2013). Effectiveness of empathy in general practice: a systematic review. British Journal of General Practice, 63(606), e76-e84.

Derntl, B., Finkelmeyer, A., Voss, B., Eickhoff, S.B., Kellermann, T., Schneider, F., \& Habel, U. (2012). Neural correlates of the core facets of empathy in schizophrenia. Schizophrenia Research, 136(1-3), 70-81.

Deutsch, F., \& Madle, R. A. (2009). Empathy: Historic and current conceptualizations, measurement, and a cognitive theoretical perspective. Human development, 18(4), 267287.

Domes, G., Heinrichs, M., Berger, C., \& Herpetz S. C. (2007). Oxytocin improves "mind reading" in humans. Biological Psychiatry, 61(6), 731-733.

Durlak, J.A., Weissberg, R.P., Dymnicki, A.B., Taylor, R.D., \& Schellinger, K.B. (2011). The impact of enhancing students' social and emotional learning: A Meta-analysis of school-based universal interventions. Child Development, 82(1), 405-432.

Ebner, N.C., Kamin, H., Diaz, V., Cohen, R.A., \& MacDonald, K. (2015). Hormones as 'difference makers' in cognitive and socioemotional aging process. Frontiers in Psychology, 5, 1595.

Eisenberg, N., \& Strayer, J. (1987). Critical issues in the studies of empathy. In N. Eisenberg, \& J. Strayer (Eds.), Empathy and its Development (pp.3-14). Cambridge, England: Cambridge University Press.

Feldman-Barrett, L. (2017). How Emotions Are Made: The secret life of the brain. London, UK: Pan MacMillan.

Ferrini, R.L., \& Barrett-Connor, E.L. (1998). Sex hormones and age: A cross-sectional study of testosterone and estradiol and their bioavailable fractions in community-dwelling men.Amerucan Journal of Epidemiology, 147(8), 750-754.

Feshbach, N., \& Roe, K. (1968). Empathy in six-and seven-year-olds. Child Development, 39(1), 133-145.

Field, T., (2014). Touch. Cambridge, MA: Massachusetts Institute of Technology Press.

Figley, C.R. (1995). Compassion Fatigue: Coping with secondary traumatic stress disorder in those who treat the traumatized. London, UK: Brunner-Routledge.

Gallo. D. (1989). Educating for empathy, reason and imagination. Journal of Creative Behavior, 23(2), 98-115.

Gena, A., Krantz, P. J., McClannahan, L. E., \& Poulson, C. L. (1996). Training and generalization of affective behavior displayed by youth with autism. Journal of Applied Behavior Analysis, 29(3), 291-304. 
Gill, S.A. \& Bierema, A.M.K., (2013). On the meaning of alarm calls: A review of functional reference in avian alarm calling. Ethology, 119(6), 449-461.

Goldman, B. (2018). The Power of Kindness: Why empathy is essential in everyday life. Toronto, Canada: Harper Collins.

Gordon, M. (2009). The Roots of Empathy: Changing the world child by child. New York, NY: The Experiment.

Gouin, J. P., Carter, C. S., Pournajafi-Nazarloo, H., Glaser, R., Malarkey, W. B., Loving, T. J., ...Kiekolt-Glaser, J.K. (2010). Marital behavior, oxytocin, vasopressin, and wound healing. Psychoneuroendocrinology, 35(7), 1082-1090.

Groen, Y., Wijers, A.A., Tuchao, O., \& Althaus, M. (2013). Are there sex differences in ERPs related to processing empathy-evoking pictures? Neuropsychologia, 51(1), 142-155.

Grühn, D., Rebucal, K., Diehl, M., Lumley, M., \& Labouvie-Vief, G. (2008). Empathy across the adult lifespan: Longitudinal and experience-sampling findings. Emotion, 8(6), 753765.

Hampson, E., van Anders, S. M., \& Mullin, L. I. (2006). A female advantage in the recognition of emotional facial expressions: test of an evolutionary hypothesis. Evolution of Human Behaviour, 27, 401-416.

Hermans, E.J., Putman, P., \& van Honk, J. (2006) Testosterone reduces empathetic behavior: a facial mimicry study. Psychoendocrinology, 31,(7), 859-866.

Hodges, S. D. (2005). Is how much you understand me in your head or mine? In B. F. Malle, \& S. D. Hodges (Eds.), Other minds: How humans bridge the divide between self and others (pp. 298-309). New York, NY: Guilford Press.

Hodges, S.D., Keil, K.J., Kramer, A.A.I.K., Veach, D., \& Villanueva, R. (2010). Giving birth to empathy: The effects of similar experience on empathic accuracy, empathic concern and perceived empathy. Personality and Social Psychology Bulletin, 36, 348-409.

Hoffman, M. L. (1984). Interaction of affect and cognition in empathy in C.E Izard, J. Kagan, \& R.B. Vajonc (Eds.), Emotions, Cognition, and Behavior, (pp.103-131). Cambridge, UK: Cambridge University Press.

Hoffman, M.L. (1987). The contribution of empathy to justice and moral judgement. In N. Eisenberg, \& J. Strayer (Eds.), Empathy and its Development (pp.47-80). Cambridge, UK: Cambridge University Press.

Hoffman, M.L., \& Saltzein, H.D. (1967). Parental discipline and the child's moral development. Journal of Personality and Social Psychology, 5(1), 45-57. 
Hogan, R. (1969). Development of an empathy scale. Journal of Consulting and Clinical Psychology, 33, 307-316.

Hollin, C. (1994). Forensic (criminological) psychology. In A. Colman (Ed.) Companion Encyclopedia of Psychology (pp.1231-1253). London, UK: Routledge.

Jackson, P.L., Brunet, E., Meltzoff, A.N., \& Decety, J. (2006). Empathy examined through the neural mechanisms involved in imaging how I feel versus how you feel pain: An eventrelated fMRI study. Neuropsychologia, 44, 752-761.

Jolliffe, D., \& Farrington, D. P. (2004). Empathy and offending: A systematic review and metaanalysis. Aggression and Violent Behavior, 9(5), 441-476.

Joliffe, D., \& Farrington, D.P. (2006). Examining the Relationship Between Low Empathy and Bullying. Aggressive Behavior, 32, 540-550.

Kariyawasam, S.H., Zaw, F., \& Handley, S.L.(2002). Reduced salivary cortisol in children with comorbid attention deficit hyperactivity disorder and oppositional defiant disorder. Neuro Endocrinology Letters. 23(1), 45-48.

Klapwijck, E.T., Aghajani, M., Colins, O.F., Marijnissen, G.M., Popma, A., van Lang, N.D.J., ...Vermeiren, R.R.J.M. (2016). Different brain responses during empathy in autism spectrum disorder and callous unemotional traits. Journal of Child Psychology and Psychiatry, 57(6), 737-747.

Kohn, A. (1991). Caring kids: the role of the school. Phi Delta Kappan, 72(7), 496-506.

Konrath, S., \& Grynberg, D. (2016). The Positive (and Negative) Psychology of Empathy. In D.F Watt, \& J. Panksepp (Eds.), Psychology and Neurobiology of Empathy, (pp. 63108). Happauge, NY: Nova Science Publishers.

Konrath, S.H., O’Brien, E.H., \& Hsing, C. (2011). Changes in dispositional empathy in American college students over time: A meta-analysis. Personality and Psychology Review, 15(2), 180-198.

Krai, T. R. A., Stodola, D. E., Birn, R. M., Mumford, J. A., Solis, E. ... Davidson, E. (2018). Neural correlates of video game empathy training in adolescents: A randomized trial. npj Science of Learning, (3), article 13. Retrieved, September 2018, from https://www.nature.com/articles/s41539-018-0029-6

Krebs, D. (1975). Empathy and altruism. Journal of Personality and Social Psychology, 32(6), 1134.

Kret, M. E., \& De Gelder, B. (2012). A review on sex differences in processing emotional signals. Neuropsychologia, 50, 1211-1221. 
Wilkinson

Krznaric, R. (2014). Empathy: Why it matters and how to get it. New York, NY: Perigee - an imprint of Penguin Random House.

Kubzansky, L. D., Mendes, W. B., Appleton, A. A., Block, J., \& Adler, G. K. (2012). A heartfelt response: Oxytocin effects on response to social stress in men and women. Biological Psychology, 90(1), 1-9.

Kuo, P.X., Saini, E.K., Thomason, E., Schultheiss, C., Gonzalez, R., \& Volling, B.L. (2016). Individual variation in fathers' testosterone reactivity to infant distress predicts parenting behaviors with their 1-year-old infants. Developmental Psychology, 58(3), 303-314.

Lamm, C., Decety, J., \& Singer, T. (2011). Meta-analytic evidence for common and distinct neural networks associated with directly experienced pain and empathy for pain. NeuroImage, 54(3), 2492-2502.

Lauria-Horner, B.A., Kutcher, S., \& Brooks, S.J. (2004). The feasibility of a mental health curriculum in elementary school. Canadian Journal of Psychiatry, 49(3), 129-132.

Leibenluft, E., Gobbini, M.I., Harrison, T., \& Haxby. J.V. (2004). Mothers' neural activation response to pictures of their children and other children. Biological Psychiatry, 56(4), 225-232.

Loudin, J.L., Loukas, A., \& Robinson, S. (2003). Relational aggression in college students: Examining the roles of social anxiety and empathy. Aggressive Behavior, 29(5), 430439.

Mayer, J.D., Salovey, P., \& Caruso, D.R. (2004). Emotional Intelligence: Theory, Findings \& Implications. Psychological Enquiry, 15(3), 197-215.

McBurnett, K.M., Lahey, B.B., Rathouz, P.J., \& Loeber, R. (2000). Low salivary cortisol and persistent aggression in boys referred for disruptive behavior. Archives of General Psychiatry, 57(1), 38-43.

Meyer, M.L., Masten, C.L., Ma, Y., Wang, C., Shi, Z., Eisenberger, N. I., \& Han, S. (2013) Empathy for the social suffering of friends and strangers recruits distinct patterns of brain activation. Social Cognitive and Affective Neuroscience, 8(4), 446-454.

Michalsaka, K.J., Kinzler, K.D., \& Decety, J. (2013). Age-related sex differences in explicit measures of empathy do not predict brain response across childhood and adolescence. Developmental Cognitive Neuroscience, 3, 22-32.

Morelli, S.A., Rameson, L.T., \& Lieberman, M.D. (2014). The Neural Components of Empathy: Predicting daily prosocial behavior. Social Cognitive and Affective Neuroscience, 9(1), 39-47. 
Montoya E.R., Terburg, D., Bos, P.A., \& van Honk, J., (2012). Testosterone, cortisol and serotonin as key regulators of social aggression: a review and theoretical perspective. Motivation and Emotion, 36(1), 65-73.

Müller, B. C., Leeuwen, M. L., Baaren, R. B., Bekkering, H., \& Dijksterhuis, A. (2013). Empathy is a beautiful thing: Empathy predicts imitation only for attractive others. Scandinavian Journal of Psychology. 401-406.

Olff, M., Frijling, J,L., Kubzansky, L.D., Bradley, B., Ellenbogen, M.A., Cardoso, ...van Zuidan, M. (2013). The role of oxytocin in social bonding, stress regulation and mental health: An update on the moderating effects of context and interindividual differences. Psychoneuroendochrinology, 38(9), 1883-1894.

Olsson, A., Kopsida, E., Sorjonen, K., \& Savic, I. (2016). Testosterone and estrogen impact social evaluations and vicarious emotion: a double-blind placebo-controlled study. Emotion, 16 (4), 515-523. Retrieved, April 2017, from: http://dx/doi.org/10.1037/a0039765

Oosterlaan, J., Geurts, H.M., Knol, D.L., \& Sergeant, J.A. (2005). Low basal salivary cortisol is associated with teacher-reported symptoms of conduct disorder. Psychiatry Research., 134(1), 1-10.

Ottowitz, W. E., Siedlecki, K. L., Lindquist, M. A., Dougherty, D. D., Fischman, A. J., \& Hall, J. E. (2008). Evaluation of prefrontal-hippocampal effective connectivity following 24 hours of estrogen infusion: an FDG-PET study. Psychoneuroendocrinology, 33, 1419 1425 .

Paleari, F. G., Regalia, C., \& Fincham, F. (2005). Marital quality, forgiveness, empathy, and rumination: A longitudinal analysis. Personality and Social Psychology Bulletin, 31(3), 368-378.

Panksepp, J. (1998). Affective Neuroscience: The foundations of human and animal emotions. New York, NY: Oxford University Press.

Pedersen, C.A. (1997). Oxytocin control of maternal behavior regulation by sex steroids and offspring stimuli. Annals of New York Academy of Sciences, 807, 126-145.

Perry, B. (1997). Incubated in Terror: Neurodevelopmental Factors in the Cycle of Violence. In J.D. Osofsky (Ed.), Children in a Violent Society (pp. 124-149). New York, NY: Guildford Press.

Pfeifer, J.H., Iacobonia, M., Mazziottaa, J.C., \& Dapretto, M. (2008). Mirroring others' emotions relates to empathy and interpersonal competence in children. NeuroImage, 39(4), 20762085

Pollack, W. (1998). Real Boys. An Owl Book, New York, NY: Henry Holt \& Co. 
Popma, A., Doreleijers, T.A., Jansen, L.M., Van Goozen, S.H., Van Engeland, H., \& Vermeiren, R. (2007). The diurnal cortisol cycle in delinquent male adolescents and normal controls. Neuropsychopharmacology, 32(7), 1622-1628.

Preston, S. D. (2013). The origins of altruism in offspring care. Psychological Bulletin, 139(6), 1305-1341.

Prinz, J. (2011). Against empathy. The Southern Journal of Philosophy, 49(S1), 214-231.

Reeve, S.A., Reeve, K.F., Townsend, D.B., \& Poulson, C.I. (2007). Establishing a generalized repertoire of helping behavior in children with autism. Journal of Applied Behavior Analysis, 40(1), 123-136.

Rifkin, J. (2009). The Empathic Civilization: The race to global consciousness in a world in crisis. New York, NY: Penguin.

Rimmele, U., Hediger, K., Heinrichs, M., \& Klaver, P. (2009). Oxytocin makes a face in memory familiar. Journal of Neuroscience, 29(1), 38-42.

Rowling, J.K. (2008, June 5). The Fringe Benefits of Failure and the Importance of Imagination". Paper presented at the Annual Meeting of the Harvard Alumni Association, Boston, MA, USA. Retrieved February, 2018 from: https://www.ted.com/talks/jk_rowling_the_fringe_benefits_of_failure

Schewe, P. A. (2007). Interventions to prevent sexual violence. In Doll, L., Bonzo, S., Sleet, D., \& Mercy, J. (Eds), Handbook of injury and violence prevention, 223-240. New York, NY: Springer.

Schewe, P. A., \& O'Donohue, W. (1993). Sexual abuse prevention with high-risk males: The roles of victim empathy and rape myths. Violence and Victims, 8(4), 339-351.

Schonert-Reichl, K.A., Smith, V., Zaidman-Zait, A., \& Hertzman, C. (2012). Promoting Children's Prosocial Behaviors in School: Impact of the "Roots of Empathy" Program on the Social and Emotional Competence of School-Aged Children. School Mental Health, 4(1), 1-21. Retrieved January 2018 at http://cemh.lbpsb.qc.ca/professionals/RootsofEmpathy.pdf .

Schrandt, J., Buffington-Townsend, D., \& Poulson, C.L. (2009). Teaching empathy skills to children with autism. Journal of Applied Behaviour Analysis, 42(1), 17-32.

Schulte-Ruther, M., Markowitsch, H.J., Fink, G.R., \& Piefke, M. (2007). Mirror neuron a theory of mind mechanism involved in face-to-face interactions: a functional magnetic resource imaging approach to empathy. Journal of Cognitive Neuroscience, 19(8), 1354-1372. 
Schumann, K., Zaki, J., \& Dweck, C.S. (2014). Addressing the empathy deficit: Beliefs about the malleability of empathy predict effortful responses when empathy is challenging. Journal of Personality and Social Psychology, 107(3), 475-493.

Sethre-Hofstad, L., Stansbury, K., \& Rice, M. A. (2002). Attunement of maternal and child adrenocortical response to child challenge. Psychoneuroendocrinology, 27(6), 731-747.

Shanafelt, T.D., West, C., Zhao, X., Novotny, P., Kolars, J., \& Habermann, T. (2005) Relationship between increased personal wellbeing and enhanced empathy among internal medicine residents. Journal of General Internal Medicine, 7, 559-564.

Sigman, A. (2012). Time For a View on Screen Time. Archives of Diseases in Childhood, 97(11), 935-942.

Smith, A. (2006). Cognitive empathy and emotional empathy in Human Behavior aEvolution. The Psychological Record, 56, 3-21.

Steffgen, G., König, A., Pfetsch, J., \& Melzer, A. (2011). Cyberpsychology, Behavior, and Social Networking. Liebert Open Access, 14(11), 643-648. Retrieved, May 2017, from: https://doi.org/10.1089/cyber.2010.0445

Striepens, N., Kendrick, K.M., Maier, W., \& Hurlemann, R. (2011). Prosocial effects of oxytocin and clinical evidence for its therapeutic potential. Frontiers in Neuroendocrinology 32, 426-450.

Tehrani, N. (2010). Compassion fatigue: experiences in occupational health, human resources, counselling and police. Occupational Medicine, 60(2), 133-138.

Tennes, K., \& Kreye, M. (1985). Children's adrenocortical responses to classroom activities and tests in elementary school. Psychosomatic Medicine. 47(5), 451-460.

Thomas, G., \& Fletcher, G. (2003). Mind-reading accuracy in intimate relationships: assessing the roles of the relationship, the target, and the judge. Journal of Personality and Social Psychology, 85(6), 1079.

Thorne, B. (1993). Gender Play: Girls and Boys in School. New Brunswick, NJ: Rutgers University Press.

Twenge, J., Konrath, S., Foster, J., Campbell, W. K., \& Bushman, B. (2008). Egos inflating over time: a cross-temporal meta-analysis of the Narcissistic Personality Inventory. Journal of Personality, 76(4), 875-902; discussion 903-828.

Unger, M. (2009). The we generation: raising socially responsible kids. Toronto, ON: McLelland \& Stewart. 
Van Honk, J., Schutter, D.J., Bos, P.A., Kruijt, A.W., Lentjes, E.G., \& Baron-Cohen, S. (2011). Testosterone administration impairs cognitive empathy in women depending on second-to-fourth digit ratio. Proceedings of the National Academy of Sciences of the United States of America, 108(8), 3448-3452.

Van Ijzendoorn, M.J., \& Bakermans-Kraneburg, M.J. (2012). A sniff of trust: Meta-analysis of the effects of intranasal oxytocin administration on face recognition, trust to in-group, and trust to out-group. Psychoneuroendocrinology, 37(3), 438-443.

Vescio, T. K., Sechrist, G. B., \& Paolucci, M. P. (2003). Perspective taking and prejudice reduction: the mediational role of empathy arousal and situational attributions. European Journal of Social Psychology, 33(4), 455-472.

Watt, D.F. (2007). Toward a neuroscience of empathy: Integrating affective and cognitive perspectives. Neuropsychoanalysis, 9(2), 119-140.

Wilkinson, I.G. (2016). Why some children come to school with "baggage": The effects of trauma due to poverty, attachment disruption and disconnection on social skills and relationships. Canadian Journal of Family and Youth, 8(1), 173-203.

Wilkinson, I.G. (2017). Bullying in Canada in the $21^{\text {st }}$ century: The moral obligations of parents, teachers, schools and governments. International Journal of Children's Rights, 25(1), $1-31$.

Williams, A., O’Driscoll, K., \& Moore, C. (2014). The influence of empathic concern on prosocial behavior in children. Frontiers in Psychology, 5, 425. Retrieved, January 2018, from: http://doi.org/10.3389/fpsyg.2014.00425

Wilson, J.P., \& Thomas, R.B. (2004). Empathy in the Treatment of Trauma and PTSD. New York, NY: Brunner-Routledge.

Yamasue, H., Kuwabara, H., Kawakubo, Y., \& Kasai, K. (2009). Psychiatry and Clinical Neurosciences, 63(2), 129-140. Retrieved, April, 2017 http://onlinelibrary.wiley.com/doi/10.1111/j.1440-1819.2009.01944.x/full

Zahn-Waxler, C., Radke-Yarrow, M. Wagner, E., \& Chapman, M. (1992). Development of concern for others. Developmental Psychology, 28(1), 126-136

Zaki, J. (2014). Empathy: A motivated account. Psychological Bulletin, 140(6), 1608-1647. 